\section{Evapotranspiration from Spider and Jade Plants Can Improve Relative Humidity in an Interior Environment}

\author{
Eric W. Kerschen ${ }^{1,3}$, Caleb Garten ${ }^{1,4}$, Kimberly A. Williams ${ }^{2,5}$, \\ and Melanie M. Derby ${ }^{1,6,7}$
}

AdDitional Index wORDs. Chlorophytum, Crassula, interiorscape, passive humidification, transpiration

Summary. Plants in the interiorscape have many documented benefits, but their potential for use in conjunction with mechanical heating, ventilation, and air conditioning (HVAC) systems to humidify dry indoor environments requires more study. In this research, evaporation and evapotranspiration rates for a root medium control, variegated spider plants (Chlorophytum comosum), and green jade plants (Crassula argentea) were measured over 24 hours at $25 \%$ and $60 \%$ relative humidity $(\mathrm{RH})$ and $20{ }^{\circ} \mathrm{C}$ to generate data for calculation of the leaf surface area and number of plants necessary to influence indoor humidity levels. Evaporation and evapotranspiration rates were higher for all cases at $25 \% \mathrm{RH}$ compared with $60 \% \mathrm{RH}$. At $25 \% \mathrm{RH}$ during lighted periods, evapotranspiration rates were $\approx 15 \mathrm{~g} \cdot \mathrm{h}^{-1}$ for spider plants and $8 \mathrm{~g} \cdot \mathrm{h}^{-1}$ for jade plants. Spider plants transpired during lighted periods due to their C3 photosynthetic pathway, whereas jade plants had greater evapotranspiration rates during dark periods - about $11 \mathrm{~g} \cdot \mathrm{h}^{-1}$ - due to their crassulacean acid metabolism (CAM) photosynthetic pathway. A combination of plants with different photosynthetic pathways (i.e., C3 and CAM combination) could contribute to greater consistency between evapotranspiration rates from day to night for humidification of interior spaces. Using the measured data, calculations indicated that $32,300 \mathrm{~cm}^{2}$ total spider plant leaf surface area, which is 25 spider plants in 4-inch-diameter pots or fewer, larger plants, could increase the humidity of an interior bedroom from $20 \% \mathrm{RH}$ to a more comfortable $30 \% \mathrm{RH}$ under bright interior light conditions.

$\mathrm{P}$ oviding a comfortable and healthy environment for building occupants is critical, as people spend more than $90 \%$ of their time indoors (Moschandreas, 1981). In the United States, buildings consume $40 \%$ of primary energy annually, and conditioning

This manuscript has been assigned Contribution no. 16-373-J from the Kansas Agricultural Experiment Station (KAES)

We gratefully acknowledge Leigh Murray and Ye Li at the Kansas State University Statistics Consulting Lab and Steven Eckels and the Institute for Environmental Research for the use of the facilities.

Mention of a trademark, proprietary product, or vendor does not constitute a guarantee or warranty of the product by Kansas State University or KAES and does not imply it approval to the exclusion of other products or vendors that may also be suitable.

${ }^{1}$ Department of Mechanical and Nuclear Engineering, Kansas State University, 3002 Rathbone Hall, Manhattan, KS 66506

${ }^{2}$ Department of Horticulture and Natural Resources, Kansas State University, 2021 Throckmorton Plant Sciences Center, Manhattan, KS 66506

${ }^{3}$ Undergraduate research assistant.

${ }^{4}$ Graduate research assistant.

${ }^{5}$ Professor.

${ }^{6}$ Assistant professor.

${ }^{7}$ Corresponding author. E-mail: derbym@ksu.edu. doi: 10.21273/HORTTECH03473-16 of residential spaces consumes nearly $50 \%$ of that energy (Energy Information Administration, 2009). During heating season, HVAC systems use energy to increase indoor air temperature while subsequently reducing $\mathrm{RH}$. Without supplemental humidification, indoor $\mathrm{RH}$ may be as low as $10 \%$ in cold climates (Kalamees et al., 2009; Nordström et al., 1994; Reinikainen et al., 1991). Acceptable building humidity levels are governed by American Society of Heating, Refrigerating, and Air-Conditioning Engineers (ASHRAE) Standard 55; upper limits on humidity are imposed to prevent mold and structural damage, but there are currently no building humidity lower limits. Therefore, many commercial and most residential buildings do not control humidities in the low humidity range $(<40 \% \mathrm{RH})$ during heating season.

Low humidities can have adverse health consequences on building occupants (Sterling et al., 1985), such as increased eye irritation (McCulley et al., 2006) and skin dryness (Sunwoo et al., 2006). The survival of many pathogens and their transmission are sensitive to humidity levels, with increased transmission at lower humidities (Lowen et al., 2007; Shaman and Kohn, 2009; Yang and Marr, 2011).

Due to the impact of low humidity on building occupants and the desire to reduce building energy consumption, passive or low-energy humidification approaches are of increasing interest. Plants can influence the humidity of an interior environment through transpiration (water movement through a plant and water vapor emission from foliage) and evaporation (conversion of water to vapor at the surface of root medium), the combination of which is evapotranspiration. Many low-light plant species can grow indoors under existing lighting conditions (DelPrince, 2013; Manaker, 1997; Pennisi and van Iersel, 2012), reducing or eliminating the need for additional energy for lighting. Light can also be supplemented in interior environments to optimize plant longevity (DelPrince, 2013).

Researchers have examined the humidification effects of plants on indoor office environments (Lohr, 1992; Lohr and Pearson-Mims, 1996; Wolverton and Wolverton, 1996; Wood et al., 2006). Lohr (1992) studied the effects on plants in two offices with room temperatures of $22{ }^{\circ} \mathrm{C}$ : one office contained a variety of plants, including varieties of Peperomia (Piperaceae family) and chinese evergreen (Aglaonema sp.), and one control office

\begin{tabular}{llll}
\hline $\begin{array}{l}\text { Units } \\
\text { To convert U.S. to } \\
\text { SI, multiply by }\end{array}$ & U.S. unit & SI unit & $\begin{array}{l}\text { To convert SI to } \\
\text { U.S., multiply by }\end{array}$ \\
\hline 0.3048 & $\mathrm{ft}$ & $\mathrm{m}$ & 3.2808 \\
0.0283 & $\mathrm{ft}^{3}$ & $\mathrm{~m}^{3}$ & 35.3147 \\
2.54 & inch(es) $_{\text {inch }}^{2}$ & $\mathrm{~cm}$ & 0.3937 \\
6.4516 & $\mathrm{~cm}^{2}$ & 0.1550 \\
16.3871 & inch $^{3}$ & $\mathrm{~cm}^{3}$ & 0.0610 \\
28.3495 & $\mathrm{oz}$ & $\mathrm{g}$ & 0.0353 \\
33.9057 & $\mathrm{oz} / \mathrm{yard}^{2}$ & $\mathrm{~g} \cdot \mathrm{m}^{-2}$ & 0.0295 \\
6.8948 & $\mathrm{psi}$ & $\mathrm{kPa}$ & 0.1450 \\
$\left({ }^{\circ} \mathrm{F}-32\right) \div 1.8$ & ${ }^{\circ} \mathrm{F}$ & ${ }^{\circ} \mathrm{C}$ & $\left({ }^{\circ} \mathrm{C} \times 1.8\right)+32$
\end{tabular}


contained no plants. The plants increased office humidity to $30 \% \mathrm{com}$ pared with $25 \% \mathrm{RH}$ in the control office. Further work examined the effects of potted plants in a computer laboratory; humidity was not significantly altered, but particulate matter accumulation decreased by as much as $20 \%$ in the presence of plants (Lohr and Pearson-Mims, 1996). In a residential study, the presence of plants in a home increased RH by more than $10 \%$ and decreased airborne microbes by more than 30\% (Wolverton and Wolverton, 1996). Peace lily (Spathiphyllum 'Sweet Chico') and dracaena (Dracaena 'Janet Craig') plants were field-tested in Australian offices during the heating season (Wood et al., 2006). The plants did not significantly influence room humidity but they reduced total volatile organic compounds levels.

Plant-based systems show potential for humidifying, removing indoor pollutants, and providing psychological benefits (Dravigne et al., 2008; Fjeld, 2000; Laviana et al., 1983). The majority of previous plant-based humidification research was field tests conducted in offices or residences. This study quantifies evapotranspiration rates from two common indoor plant species with different photosynthetic pathways in a controlled environmental chamber. The research objectives include 1) quantification of evaporation rates from a root medium, and evapotranspiration rates from variegated spider plants and green jade plants, at two indoor humidity levels; 2 ) evaluating the impact of the diurnal light cycle on transpiration for two plant species with different photosynthetic pathways; and 3) calculation of the plants' potential impact on RH of a single interior bedroom, such as in a skilled nursing facility (SNF).

\section{Materials and methods}

TREATMENTS AND EXPERIMENTAL APPARATUS. A root medium and plants were tested in an environmental chamber to determine their evaporation and evapotranspiration rates. The six treatment combinations were 1) pots of root medium with no plants (control), 2) pots of root medium with variegated spider plants, and 3 ) pots of root medium with green jade plants. Each experimental unit of five test objects were subjected to $25 \%$ or $60 \% \mathrm{RH}$ at a constant temperature of $20^{\circ} \mathrm{C}$. The root medium control consisted of $70 \%$ low-humified Canadian sphagnum peatmoss: $30 \%$ perlite [v/v (Sun Gro Horticulture, Agawam, MA)] initially moistened to match moisture levels in the pots containing plants. Variegated spider plant, a member of the Asparagaceae family with a C3 photosynthetic pathway, and green jade, a member of the Crassulaceae family with a CAM photosynthetic pathway, were selected because they are commonly found in interiorscapes and because they have different photosynthetic pathways. The spider and jade plants were transplanted into round, green pots [ 4 inch diameter, $370 \mathrm{~cm}^{3}$ volume (Landmark Plastic Corp., Akron, $\mathrm{OH})$ ], and filled with the same root medium as the control pots. Results obtained represented moisture loss from five pots for each of the three treatments at two RH levels. Each treatment combination was replicated twice at a constant temperature of $20^{\circ} \mathrm{C}$.

ENVIRONMENTAL CHAMBER. Runs were conducted in a $570-\mathrm{ft}^{3}$ environmental chamber at the Institute for Environmental Research at Kansas State University, Manhattan. Air at the desired temperature and moisture content flowed into the chamber via an air system supply on one side of the chamber and a return on the opposite side (Fig. 1). With the exception of these air ducts, the chamber was completely sealed. To verify that chamber conditions were identical to set conditions, temperature and $\mathrm{RH}$ measurements were taken $1.8 \mathrm{~m}$ from the test objects using thermocouple probes (TMQSS-125U6; OMEGA Engineering, Stamford, $\mathrm{CT})$ and a digital humidity probe (PCMini52 Humidity/Temperature Mini Probe; Michell Instruments, Ely, England). Before each test, chamber air pressure was also measured using a handheld barometer (Druck DPI 740; GE Measurement and Control, Billerica, MA). Measured chamber pressure ranged from 97 to $99 \mathrm{kPa}$. All sensors were monitored by a computer located outside the environmental chamber; computers and investigators were not present in the environmental chamber during testing. Because air velocity impacts mass transfer, an anemometer (AIRFLOW AV2; TSI, Shoreview, MN) with a remote vane probe (Al5961) was used to determine air velocity. The probe was moved along the chamber wall surface, which contains a pattern of small holes for air flow. Air velocity at the wall varied from 0.5 to $\mathrm{ltt} / \mathrm{s}$, with an average value of $0.73 \mathrm{ft} / \mathrm{s}$. Air velocity directly above the test objects was found to be $0 \mathrm{ft} / \mathrm{s}$; therefore, the test objects were in quiescent conditions.

Test stand. The test stand consisted of a precision scale, soil moisture probes, temperature probes, and a hygrometer for data collection (Fig. 1) as well as fluorescent bulbs as the light source in the dark environmental chamber. Experiments were conducted for groups of five test objects (i.e., pots of root medium, spider plants, or jade plants). An electronic, precision scale $[ \pm 0.1 \mathrm{~g}$ accuracy (GP30KS; A\&D, Tokyo, Japan)] recorded total weight of the five objects. All weight loss was assumed to be water and was used to determine evaporation or evapotranspiration rate. Root medium moisture content was controlled and monitored. Each pot contained a soil moisture probe (Decagon 5TM Soil Moisture and Temperature Probes; Decagon Devices, Pullman, WA). Probes were calibrated according to the Decagon manual (Cobos and Chambers, 2010): a known amount of root medium was completely dried, and soil moisture probe output was recorded. Known volumes of water were also added to obtain a calibration,

$$
\theta=5.031 \cdot 10^{-4} x-0.0143
$$

where $\theta$ is the volumetric water content (cubic centimeters per cubic centimeter), and $x$ is the raw output of the sensor. The calibration was linear with an $R^{2}$ value of 0.997 . Temperature and RH were measured 8 inches above the root medium surface using two temperature probes (TMQSS$125 \mathrm{U}-6)$ and a hygrometer probe (General Eastern Optica Series Chilled Mirror Hygrometer; GE Measurement and Control).

EXPERIMENTAL LIGHTING CONDITIONs. Plants of each species were obtained from stock maintained in the Kansas State University Throckmorton Plant Sciences Center greenhouses. The plants were acclimated indoors for 2 months to adjust to prescribed lighting conditions. Light was provided by two fluorescent bulbs (T5; Sunblaster Lighting, Kelowna, BC, Canada) and the same light schedule was used in the environmental chamber and acclimation area, with synchronized light on/off 


\section{Top view}

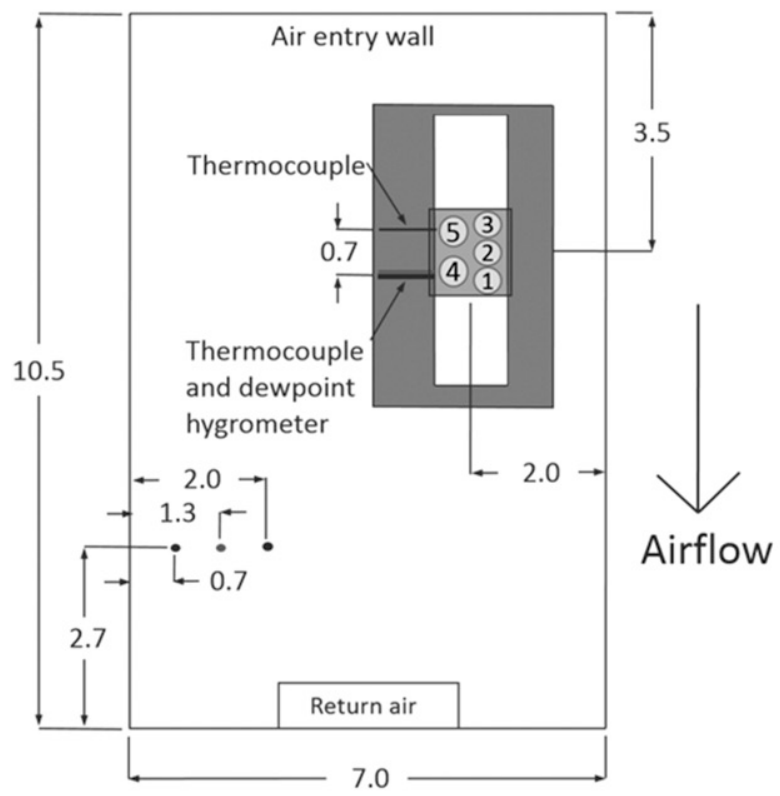

\section{Front view}

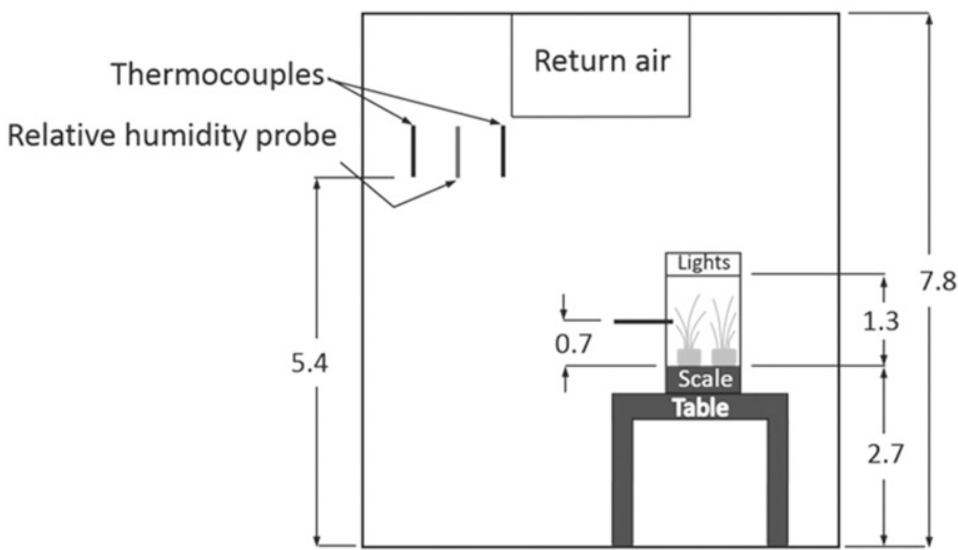

Fig. 1. Test objects (root medium control, spider plants, and jade plants) and sensor positions in the environmental chamber at Kansas State University's Institute for Environmental Research, Manhattan, to quantify the effect of root medium evaporation and plant transpiration on relative humidity. This layout was used for each of 12 runs of the experiment. All measurements are in feet; $1 \mathrm{ft}=0.3048 \mathrm{~m}$.

times (Fig. 2). Each test began with at least $5.5 \mathrm{~h}$ of light (Light 1 ) followed by $1 \mathrm{l} \mathrm{h}$ of darkness (Dark) and then light (Light 2). This 24-h testing procedure allowed the experiments to capture the effects of diurnal lighting changes on the test objects. The lights did not interfere with plant foliage.

To quantify the amount of light the test objects received, photosynthetic photon flux $(P P F)$ was measured (model LI-250 light meter; LI-COR, Lincoln, NE). A PPF of $81 \mu \mathrm{mol} \cdot \mathrm{m}^{-2} \cdot \mathrm{s}^{-1}$ was measured at the top of the root medium ( $1 \mathrm{ft}$ from the light source) and $129 \mu \mathrm{mol} \cdot \mathrm{m}^{-2} \cdot \mathrm{s}^{-1}$ at foliage canopy ( 7 inches from the light source). Using unit conversions (Thimijan and Heins, 1983) to allow for comparison, these light levels would be considered in a "high" category in an interior environment (DelPrince, 2013; Manaker, 1997) that may require supplemental lighting to achieve. The test objects were subjected to lighting conditions comparable to a bright interior environment that would maximize plant evapotranspiration rate.

EXPERIMENTAL PROCEDURE. The experiment consisted of a total of 12 runs; runs were replicated for six treatment combinations: the root medium control, spider plants, and jade plants (three treatments) at two humidities $(25 \%$ and $60 \% \mathrm{RH})$, all at a constant temperature of $20{ }^{\circ} \mathrm{C}$. Before testing, the order of the 12 runs was randomized. For each run, root medium moisture content was prepared to a target range of 0.28 to $0.35 \mathrm{~cm}^{3}$ water per cubic centimeter of root medium. Initial soil moisture content measurements were then taken, and water was slowly added to each pot to raise the moisture content to the desired level. After root medium moisture reached equilibrium, the five pots were moved into the environmental chamber and placed on the precision scale; a root medium moisture probe was inserted into each pot. Chamber air speed and pressure measurements were taken. The chamber was sealed and reached steady state in 20 to 40 min, after which automated data collection commenced, measuring temperature, humidity, root medium moisture content, and weight of the five pots. Data were logged for $24 \mathrm{~h}$, after which the environmental chamber was opened to obtain posttest air speed and pressure measurements. Data were then compiled and analyzed.

LEAF AREA MEASUREMENTS. Because plant transpiration is dependent on leaf surface area, leaf areas of each plant were measured following experimental testing. All leaves were removed from the plants and sealed between transparent laminating sheets. The transparent sheets were scanned to determine total surface area of each plant's leaves using a leaf area meter (LI-3000C, LI-COR).

Statistical analyses. The evaporation/evapotranspiration rate data for the steady-state portion of each lighting period (Fig. 2) was statistically analyzed. For Light 1 , the analyzed time frame was the period between 2.5 and $4.5 \mathrm{~h}$ after the experiment began. During Dark conditions, data were analyzed 8 to $10 \mathrm{~h}$ after the light was turned off. For Light 2, data were analyzed from 2.5 to $4.5 \mathrm{~h}$ after the light was turned on. Analysis of variance test was conducted using SAS software (version 9.3; SAS Institute, Cary, NC) to evaluate interactions of treatment variables of the two RH conditions, three treatments (i.e., control, spider plants, and jade plants), and three lighting conditions (i.e., Light 1, Dark, Light 2) for interactions (Fig. 2). F-tests were calculated for simple effects, and means were separated with Tukey's pairwise comparison at a $95 \%$ confidence interval ( $\alpha=0.05$ ); thereby, $P<0.05$ is considered statistically significant. 


\section{Results and discussion}

EVAPORATION AND EVAPOTRANSPIRATION. Only evaporation occurred in the root medium control due to the lack of transpiration from any plants. The control showed the least variation in evaporation rate during lighting periods with evaporation rates between $\approx 5$ and $9 \mathrm{~g} \cdot \mathrm{h}^{-1}$ at $25 \% \mathrm{RH}$ and 2.5 and $5 \mathrm{~g} \cdot \mathrm{h}^{-1}$ at $60 \% \mathrm{RH}$ (Figs. $3 \mathrm{~A}$ and $4 \mathrm{~A})$. Both plant species showed a distinct change in evapotranspiration between lighting intervals due to evaporation from their root medium and transpiration from the plants themselves. For the spider plants, maximum evapotranspiration occurred during the lighted period, up to $16 \mathrm{~g} \cdot \mathrm{h}^{-1}$ (Figs. 3B and $4 \mathrm{~B}$ ). In contrast, the jade plants exhibited more constant evapotranspiration levels. During dark periods, jade evapotranspiration exceeded that of the spider plants (Figs. 3C and 4C). At $25 \% \mathrm{RH}$, evapotranspiration rates were $\approx 11 \mathrm{~g} \cdot \mathrm{h}^{-1}$ for the group of five jade plants and $6 \mathrm{~g} \cdot \mathrm{h}^{-1}$ for the group of five spider plants in the dark period (Fig. 3). Evapotranspiration rates were even lower in the dark at $60 \% \mathrm{RH}$, around $4.5 \mathrm{~g} \cdot \mathrm{h}^{-1}$ and $3 \mathrm{~g} \cdot \mathrm{h}^{-1}$ for jade and spider plants, respectively (Fig. 4). This trend is due to differences in their photosynthetic mechanisms.

EFFECT OF LIGHT AND DARK ON EVAPORATION RATES. Lighting conditions significantly impacted evaporation rates of the plant species in this study. The spider and jade plants experienced transient evapotranspiration rates related to the change from dark to light and light to dark. The effect was more pronounced in the transition from Dark to Light 2 for the spider and jade plants (Figs. 3B, 3C, 4B, and 4C). Transient changes in observed evapotranspiration rates are likely due to stomatal opening and behavior.

The 25\% RH environment resulted in statistically different evaporation rates across lighting conditions for the root medium $(P=0.01)$ and differing evapotranspiration rates across lighting conditions for the spider plants $(P<0.01)$ and jade plants $(P<0.01)$. At $25 \% \mathrm{RH}$, steady-state evaporation rates from the control decreased by $27 \%$ from the first light period to the darkness, returning to within $12 \%$ of their initial value during the second light period. For the spider

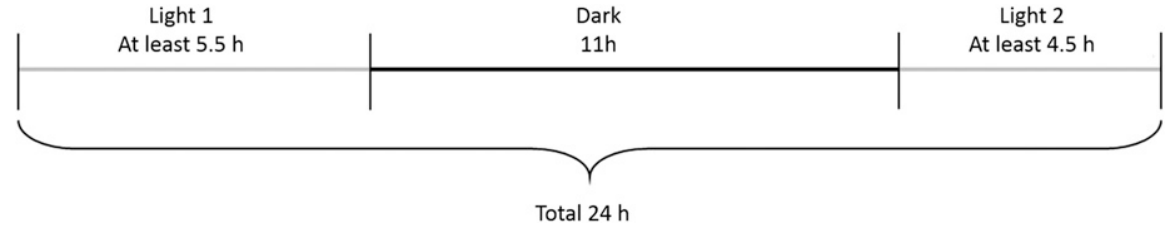

Fig. 2. Lighting schedule for root medium control, spider plants, and jade plants tested in an environmental chamber for each of 12 runs in the experiment to quantify the effect of root medium evaporation and plant transpiration on relative humidity. A dark period occurred between Light 1 and Light 2 , the first and second lighted periods, respectively, to which test objects were exposed.
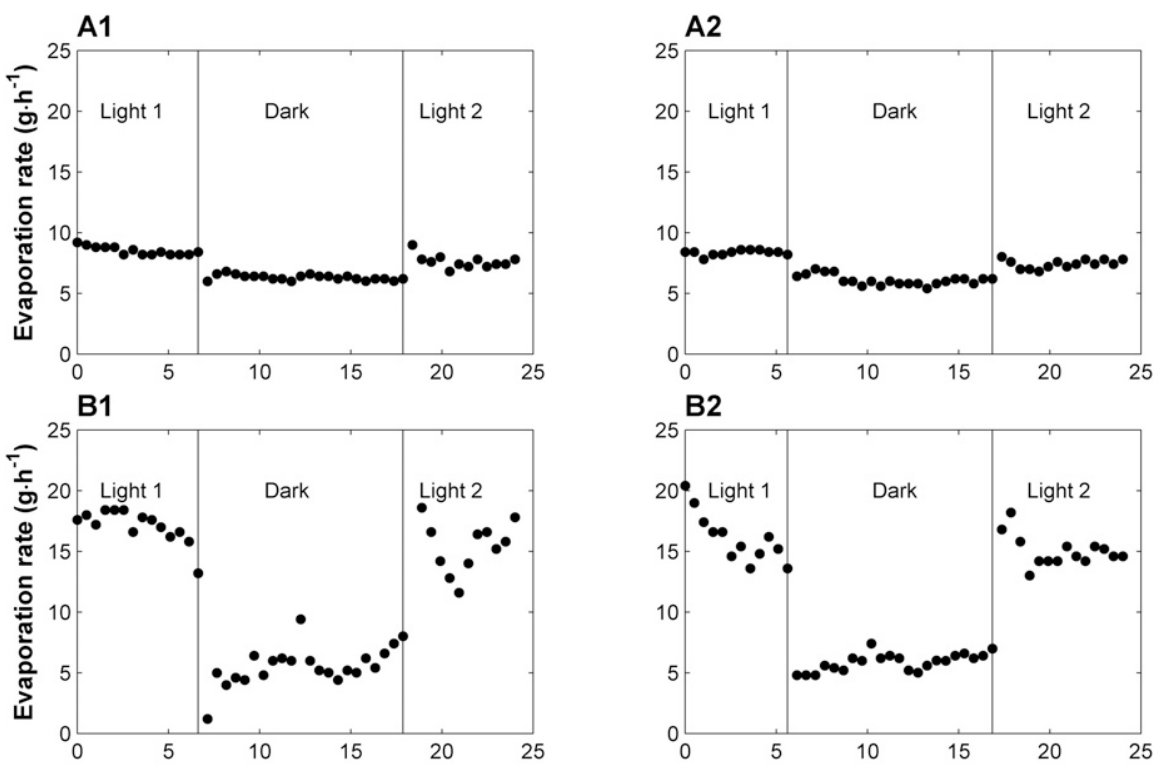

B2
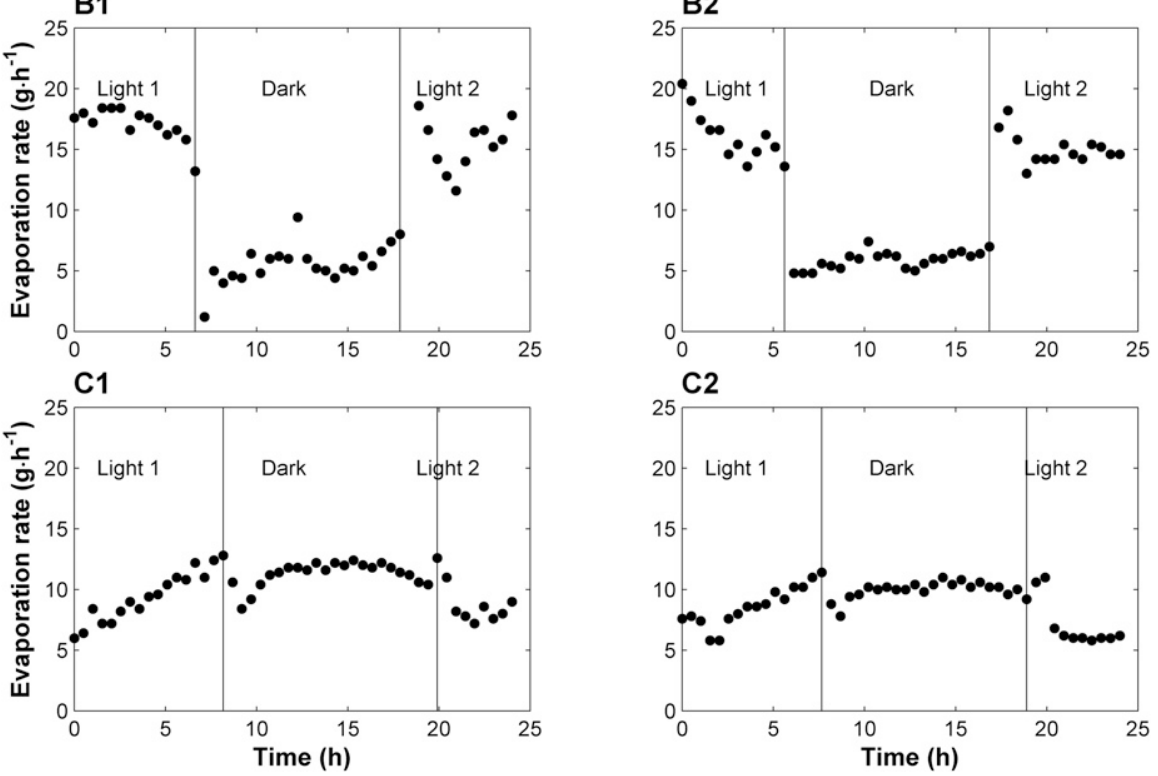

Fig. 3. Measured evaporation rates for both runs ( 1 and 2) of (A) root medium control, and measured evapotranspiration rates for $(B)$ spider plants and $(C)$ jade plants over a simulated $24-\mathrm{h}$ day at $25 \%$ relative humidity and temperature of $20{ }^{\circ} \mathrm{C}$ $\left(68.0^{\circ} \mathrm{F}\right)$ in an environmental chamber; $\mathrm{N}=1$ with five pots per experimental unit; $1 \mathrm{~g}=0.0353 \mathrm{oz}$.

plants, evaporation rates dropped sharply, by $62 \%$, during the dark period and rebounded within $10 \%$ of the initial value during the second light period. However, the jade plants exhibited the highest evapotranspiration rate during the dark period, $28 \%$ higher than the first light period (Fig. $5 \mathrm{~A})$. Since this effect of light was noted, further pairwise comparisons were conducted. For the root medium control, there was a difference between evaporation in Light 1 and Dark periods $(P=0.01)$; this may have been a result of changing volumetric water content over the course of the run (Fig. 6). There was not a difference between Dark and Light $2(P=0.13)$ or Light 1 and Light $2(P=0.28)$.

In the $25 \%$ RH environment, the spider and jade plants exhibited opposing evaporative trends (Fig. 5A). The spider plants increased evapotranspiration during lighted conditions, and a difference occurred in evapotranspiration rates between Dark and Light 1 

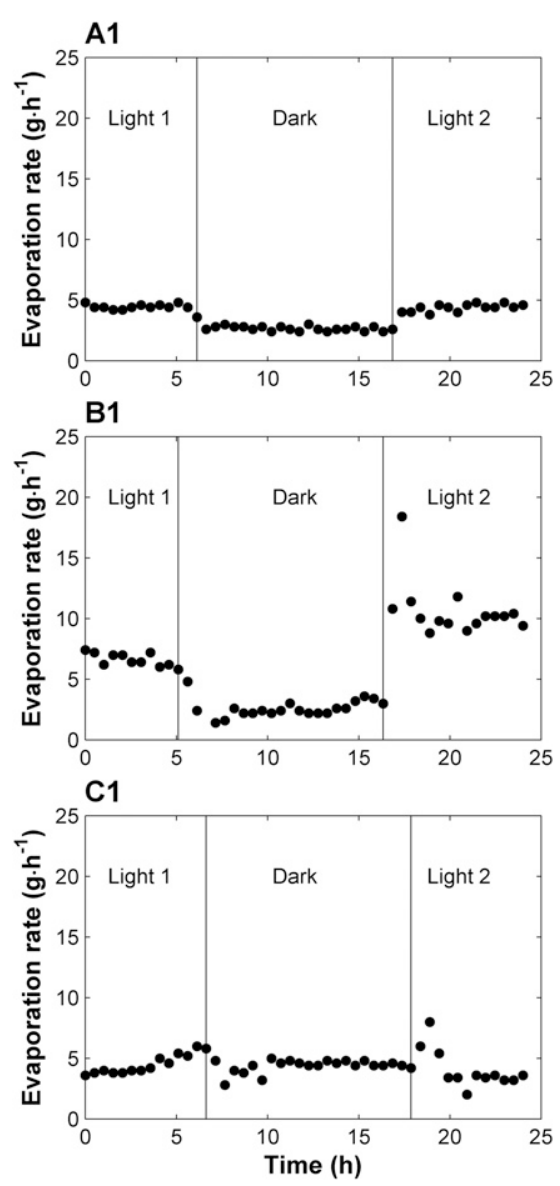

Fig. 4. Measured evaporation rates for both runs ( 1 and 2 ) of (A) root medium control, and measured evapotranspiration rates for $(B)$ spider plants and $(C)$ jade plants over a simulated $24-\mathrm{h}$ day at $60 \%$ relative humidity and temperature of $20{ }^{\circ} \mathrm{C}$ $\left(68 .{ }^{\circ} \mathrm{F}\right)$ in an environmental chamber; $\mathrm{N}=1$ with five pots per experimental unit;

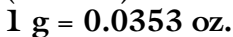

$(P<0.01)$ and Dark and Light $2(P<$ $0.01)$, but not between Light 1 and Light $2(P=0.06)$. The spider plants also had higher evapotranspiration rates during light periods compared with the evaporation rate of the root medium control and similar evapotranspiration to the root medium control during Dark periods. In the 25\% RH environment with jade plants, a difference was observed between Dark and Light $\mathrm{l}(P=0.01)$ and Dark and Light $2(P<0.01)$, but not between Light 1 and Light $2(P=0.11)$. The jade plants demonstrated identical evaporation rate to the root medium only during light periods, indicating negligible transpiration from the jade plants (Fig. 5A). The jade plants had higher evaporation rates than the root medium control during Dark periods $(P<0.01)$, indicating that the plants transpired in the darkness.

Differences in evapotranspiration rates between spider and jade plants can be explained by the plant
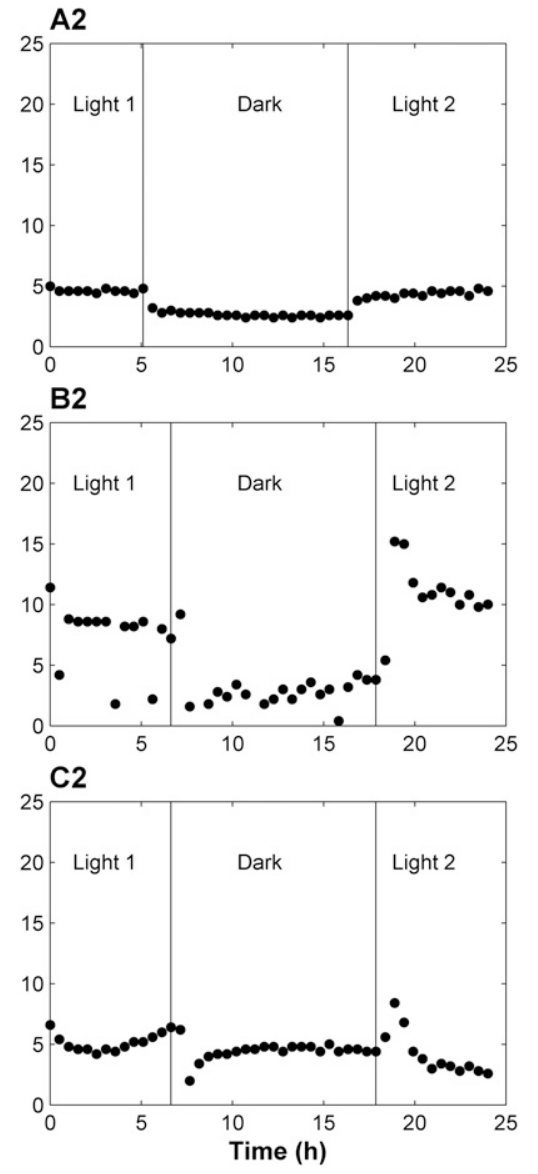

.

$$
\text { FLux }
$$

\section{FL} ing, teaf areas of five plants per species were measured to be 6466 and $4582 \mathrm{~cm}^{2}$ for spider and jade plants, respectively. It should be noted that the spider plants had variegated white and green leaves with a white strip down the middle of each leaf blade. Research has shown that stomata in white portions of leaves do not respond to photosynthetically active radiation (Roelfsema et al., 2006). Total leaf area was reported in the results, but the effective spider plant leaf area for photosynthesis was less than the reported total area.

Steady-state transpiration fluxes were estimated to account for differences in leaf area between spider and jade plants. The evaporation rate from the root medium control was subtracted from the plants' measured evapotranspiration rates to estimate transpiration, and transpiration flux was calculated using total leaf area. At $25 \% \mathrm{RH}$, transpiration fluxes for spider plants during Light 1 and Light 2 periods were 12 and $11 \mathrm{~g} \cdot \mathrm{m}^{-2} \cdot \mathrm{h}^{-1}$, respectively. During the Dark period, the evaporation rate from the root 

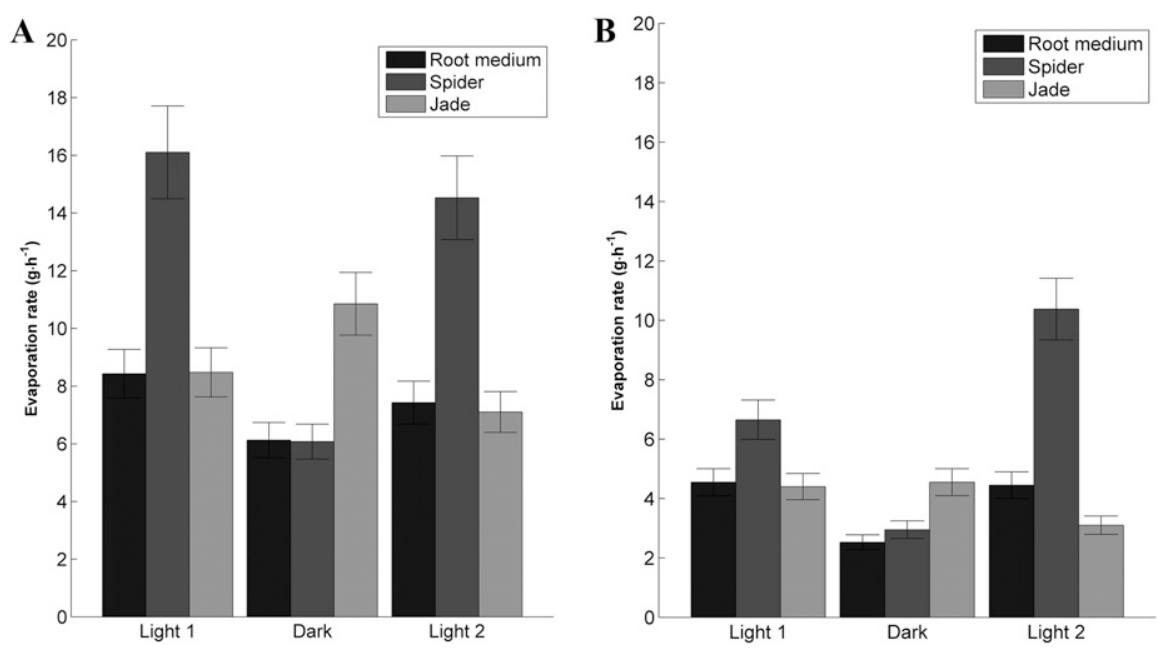

Fig. 5. Steady-state evaporation/evapotranspiration rates from the root medium control, spider plants, and jade plants at (A) $25 \%$ relative humidity ( $\mathrm{RH}$ ) and (B) $60 \% \mathrm{RH}$ in replicated runs in an environmental chamber.

media and evapotranspiration from spider plants were not different, therefore negligible transpiration occurred. In contrast, jade plant transpiration flux was $10.3 \mathrm{~g} \cdot \mathrm{m}^{-2} \cdot \mathrm{h}^{-1}$ in the Dark period, with negligible transpiration during lighted periods. Transpiration fluxes decreased for all species at $60 \% \mathrm{RH}$, with fluxes of 3.2 and $9.1 \mathrm{~g} \cdot \mathrm{m}^{-2} \cdot \mathrm{h}^{-1}$ for the spider plants during Light 1 and Light 2 periods, respectively, with negligible transpiration in the Dark period. For the jade plants, transpiration fluxes of $4.4 \mathrm{~g} \cdot \mathrm{m}^{-2} \cdot \mathrm{h}^{-1}$ were observed during the Dark period, with negligible transpiration during the lighted periods. Transpiration fluxes were similar during the period that each plant species had stomata open (i.e., light for spider plants and dark for jade plants). During periods where stomata were not open, transpiration was negligible, and moisture transport was almost entirely a consequence of evaporation from the root medium. These results may help in the estimation of required plant leaf surface area needed to humidify interior rooms.

IMPLICATIONS FOR INDOOR HUMIDIFICATION. Evapotranspiration from plants represents a method to humidify with minimal energy expenditure. Plant-based indoor humidification could be especially beneficial in SNFs because plants in an indoor environment have been shown to improve quality of life for the elderly (McGuire, 1997; Stein, 1997; Tse, $2010)$. For a typical resident room $\left(22 \mathrm{~m}^{3}\right)$ in an SNF (Ninomorua and
Cohen, 1999), the recommended ventilation rate is two air changes per hour (ASHRAE, 1999), requiring an air exchange rate of $45.3 \mathrm{~m}^{3} \cdot \mathrm{h}^{-1}$ $\left(26.7 \mathrm{ft}^{3} / \mathrm{min}\right)$. The molar air-flow rate, $\dot{n}$, can be obtained through the ideal gas law,

$$
\dot{n}=\frac{P Q}{R T}
$$

where $P$ is pressure, $Q$ is volumetric flow rate, $R$ is ideal gas constant, and $T$ is temperature. Using atmospheric pressure and a temperature of $20^{\circ} \mathrm{C}$ in Eq. [2], a molar air-flow rate of $1,833 \mathrm{~mol} \cdot \mathrm{h}^{-1}$ air was obtained. $\mathrm{RH}$, $\phi$, is defined as

$$
\left.\phi=\frac{y_{\mathrm{v}}}{y_{\mathrm{v}, \text { sat }}}\right)_{T, p}
$$

where $y_{\mathrm{v}}$ is the molar fraction of water vapor, and $y_{\mathrm{v}, \mathrm{sat}}$ is the molar fraction of water vapor at saturation at a given temperature and pressure. Therefore, additional moisture required to increase $\mathrm{RH}$ can be determined.

During heating season or dry conditions, an interior plantscape at an SNF could be augmented with potted spider plants to increase daytime $\mathrm{RH}$ and potentially improve patient well-being due to the presence of plants. To increase humidity by $10 \%$ $\mathrm{RH}, 4.3 \mathrm{~mol} \cdot \mathrm{h}^{-1}$ water must be introduced into the room. For spider plants at $25 \% \mathrm{RH}$ under tested light conditions, a constant evapotranspiration rate of $15 \mathrm{~g} \cdot \mathrm{h}^{-1}$ was estimated, based on the data shown in Fig. 5. Variegated spider plant leaf surface area of $32,300 \mathrm{~cm}^{2}$ is needed to increase humidity from $20 \% \mathrm{RH}$ to a more comfortable $30 \%$ RH. This is equivalent to 25 spider plants in 4-inch-diameter pots that could be accommodated in a small, automated greenwall, or on a light cart or windowsill display. A few, large plants would most likely result in very similar impact on humidity as this large number of small plants. Therefore, for example, three variegated spider plants in 10 -inch hanging baskets with a similar total leaf surface area could also be used. Use of nonvariegated species of spider plants would also reduce the required number of plants.

Depending on the climate, an SNF resident may desire the psychological benefits of plants without corresponding increased room moisture levels. Therefore, an interior plantscape could be rotated seasonally, with spider plants during low-humidity seasons and jade plants for high-humidity seasons. For example, 25 spider plants $\left(32,300 \mathrm{~cm}^{2}\right.$ leaf surface area) could be replaced with 20 jade plants $\left(18,330 \mathrm{~cm}^{2}\right.$ leaf surface area). The maximum evapotranspiration $\left(4.5 \mathrm{~g} \cdot \mathrm{h}^{-1}\right)$ occurs during dark conditions. According to Eq. [2] and Eq. [3], the jade plants would add $1 \mathrm{~mol} \cdot \mathrm{h}^{-1}$ water. This moisture addition would increase the $60 \%$ indoor $\mathrm{RH}$ by a modest $2.3 \%$, primarily at night. These two cases demonstrate the potential efficacy of a natural plantbased system for passive humidification. Further design work could yield superior plant species; however, study results suggested that a combination of plants with different photosynthetic pathways (i.e., C3 and CAM) might be used to manipulate evapotranspiration rates so that they are relatively consistent through the diurnal cycle or fine-tuned for the appropriate season. Although beyond the scope of this study, future research could include evaluation of evaporation rates from various plant media.

In summary, lighting significantly impacts plant evapotranspiration behavior. Transient evaporative behavior was observed for jade and spider plants as lighting changed from dark to light and light to dark. This transient behavior is likely due to stomatal opening and closing.

Plants with different photosynthetic mechanisms, such as jade and spider plants, exhibit opposing 

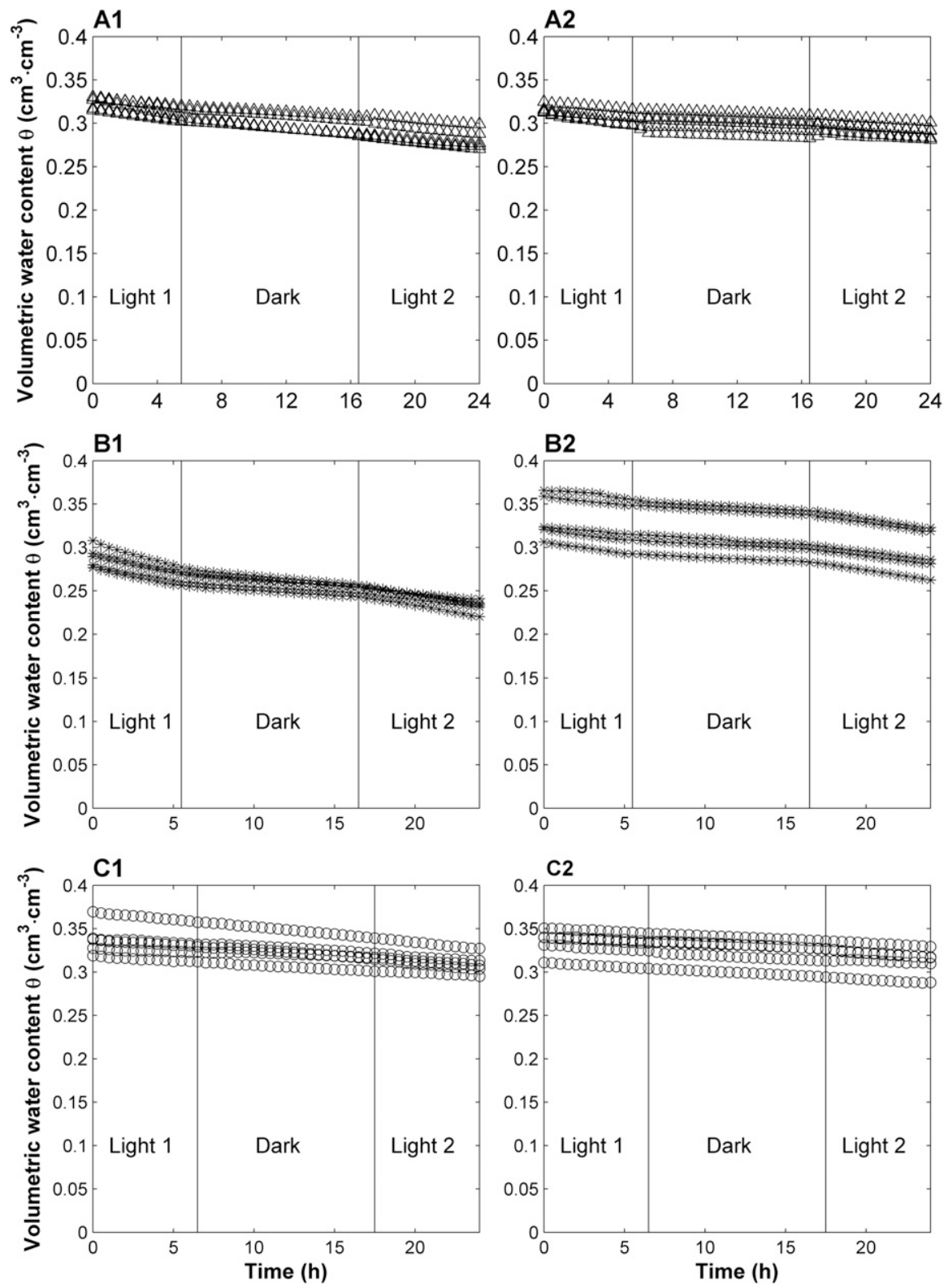

Fig. 6. Volumetric water content of (A) root medium control, (B) spider plants, and (C) jade plants over a simulated 24 -h day at (1) $25 \%$ relative humidity (RH) and $(2) 60 \% \mathrm{RH}$ at a temperature of $20^{\circ} \mathrm{C}\left(68.0^{\circ} \mathrm{F}\right)$ in an environmental chamber; $\mathrm{N}=1$ with five pots per experimental unit; $1 \mathrm{~cm}^{3}=0.0610 \mathrm{inch}^{3}$.

transpiration trends with light. For spider plants, transpiration occurs due to the $\mathrm{C} 3$ photosynthetic pathway during lighted conditions. Because jade plants have the CAM photosynthetic pathway, they exhibit transpiration during the dark.

Decreased evaporation and evapotranspiration rates correlate to increased RHs. Evaporation/evapotranspiration rates during the first lighted period at $60 \% \mathrm{RH}$ were $46 \%, 59 \%$, and $48 \%$ lower than evaporation/evapotranspiration rates observed at $25 \% \mathrm{RH}$ for root medium, spider plants, and jade plants, respectively.
Using the measured data, calculations indicated that $32,300-\mathrm{cm}^{2}$ total spider plant leaf surface area could increase the humidity of an SNF room from $20 \% \mathrm{RH}$ to a more comfortable $30 \% \mathrm{RH}$ under bright interior light conditions. This leaf surface area of variegated spider plants corresponds to about 25 plants in 4 -inch-diameter pots or three 10 -inch hanging baskets. During seasons when additional moisture is not desired, the spider plants could be replaced with jade plants to negligibly influence room humidity.

This work suggests that natural, plant-based systems have the potential to humidify low-humidity indoor environments while negligibly affecting indoor humidity levels at higher humidities. Future work could identify additional plant species and combinations as well as root media to humidify and improve indoor air quality in relation to various indoor environmental conditions.

\section{Literature cited}

American Society of Heating, Refrigerating, and Air-Conditioning Engineers (ASHRAE). 1999. Standard 62-1999, Ventilation for acceptable indoor air quality. Amer. Soc. Heating Refrigerating Air-Conditioning Eng., Atlanta, GA.

Cobos, D.R. and C. Chambers. 2010. Calibrating $\mathrm{ECH}_{2} \mathrm{O}$ soil moisture sensors. 14 Oct. 2016. <http://manuals.decagon. com/Application $\% 20$ Notes $/ 13393$ Calibrating\%20ECH2O\%20Probes_Print. pdf>.

DelPrince, J.M. 2013. Interior plantscaping: Principles and practices. Cengage Learning, Delmar, NY.

Dravigne, A., T.M. Waliczek, R.D. Lineberger, and J.M. Zajicek. 2008. The effect of live plants and window views of green spaces on employee perceptions of job satisfaction. HortScience 43:183-187.

Energy Information Administration. 2009. Residential energy consumption survey. 14 Oct. $2016 .<$ http://www.eia.gov/ consumption/residential/>.

Fjeld, T. 2000. The effect of interior planting on health and discomfort among workers and school children. HortTechnology 10:46-52.

Kalamees, T., M. Korpi, J. Vinha, and J. Kurnitski. 2009. The effects of ventilation systems and building fabric on the stability of indoor temperature and humidity in Finnish detached houses. Build. Environ. 44:1643-1650.

Laviana, J.E., R.H. Mattson, and F.H.J. Rohles. 1983. Plants as enhancers of the indoor society. Proc. Human Factors Ergonomics Soc. Annu. Mtg. p. 738-741.

Lohr, V.I. 1992. The contribution of interior plants to relative humidity in an office, p. 117-119. In: D. Relf (ed.). The role of horticulture in human well-being and social development. Timber Press, Portland, OR.

Lohr, V.I. and C.H. Pearson-Mims. 1996. Particulate matter accumulation on horizontal surfaces in interiors: Influence of foliage plants. Atmos. Environ. 30: 2565-2568.

Lowen, A.C., S. Mubareka, J. Steel, and P. Palese. 2007. Influenza virus transmission 
is dependent on relative humidity and temperature. PLoS Pathog. 3:e151.

Manaker, G.H. 1997. Interior plantscapes: Installation, maintenance and management. 3rd ed. Prentice-Hall, Upper Saddle River, NJ.

McCulley, J.P., J.D. Aronowicz, E. Uchiyama, W.E. Shine, and I.A. Butovich. 2006. Correlations in a change in aqueous tear evaporation with a change in relative humidity and the impact. Amer. J. Ophthalmol. 141:758-760.

McGuire, D.L. 1997. Implementing horticultural therapy into a geriatric longterm care facility. Act. Adaptation Aging 22:61-80.

Moschandreas, D. 1981. Exposure to pollutants and daily time budgets of people. Bull. N. Y. Acad. Med. 57:845-859.

Ninomorua, P.T. and M.H. Cohen. 1999. IAQ in nursing homes. Amer. Soc. Heating Refrigerating Air-Conditioning Eng. J. 41:34-38.

Nordström, K., D. Norbäck, and R. Akselsson. 1994. Effect of air humidification on the sick building syndrome and perceived indoor air quality in hospitals: A four month longitudinal study. Occup. Environ. Med. 51:683-688.
Pennisi, S.V. and M.W. van Iersel. 2012. Quantification of carbon assimilation of plants in simulated and in situ environments. HortScience 47:468-476.

Reinikainen, L.M., J.J. Jaakkola, and O.P. Heinonen. 1991. The effect of air humidification on different symptoms in office workers: An epidemiologic study. Environ. Intl. 17:243-250.

Roelfsema, M., K.R. Konrad, H. Marten, G.K. Psaras, W. Hartung, and R. Hedrich. 2006. Guard cells in albino leaf patches do not respond to photosynthetically active radiation, but are sensitive to blue light, $\mathrm{CO}_{2}$ and abscisic acid. Plant Cell Environ. 29:1595-1605.

Shaman, J. and M. Kohn. 2009. Absolute humidity modulates influenza survival, transmission, and seasonality. Proc. Natl. Acad. Sci. USA 106:3243-3248.

Stein, L.K. 1997. Horticultural therapy in residential long-term care. Act. Adaptation Aging 22:107-124.

Sterling, E., A. Arundel, and T. Sterling. 1985. Criteria for human exposure to humidity in occupied buildings. Amer. Soc. Heating Regrigerating Air-conditioning Engineers Trans. 91:611-622.

Sunwoo, Y., C. Chou, J. Takeshita, M. Murakami, and Y. Tochihara. 2006.
Physiological and subjective responses to low relative humidity. J. Physiol. Anthropol. 25:7-14.

Taiz, L. and E. Zeiger. 2006. Plant physiology. 4th ed. Sinauer Assoc., Sunderland, MA.

Thimijan, R.W. and R.D. Heins. 1983. Photometric, radiometric, and quantum light units of measure: A review of procedures for interconversion. HortScience 18:818-822.

Tse, M.M.Y. 2010. Therapeutic effects of an indoor gardening programme for older people living in nursing homes. J. Clin. Nurs. 19:949-958.

Wolverton, B. and J.D. Wolverton. 1996. Interior plants: Their influence on airborne microbes inside energy-efficient buildings. J. Miss. Acad. Sci. 41:99-105.

Wood, R.A., M.D. Burchett, R. Alquezar, R.L. Orwell, J. Tarran, and F. Torpy. 2006. The potted-plant microcosm substantially reduces indoor air VOC pollution: I. Office field-study. Water Air Soil Pollut. 175:163-180.

Yang, W. and L.C. Marr. 2011. Dynamics of airborne influenza A viruses indoors and dependence on humidity. PLoS One 6:e21481. 